\title{
Use of Outcome Measures in Managing Neck Pain: An International Multidisciplinary Survey
}

\author{
Joy C. MacDermid*, ${ }^{*}$, David M. Walton ${ }^{2}$, Pierre Côté ${ }^{3}$, P. Lina Santaguida ${ }^{4}$, Anita Gross ${ }^{5}$ and \\ Lisa Carlesso ${ }^{4}$ and $\mathrm{ICON}^{6}$
}

\author{
${ }^{I}$ School of Rehabilitation Sciences, McMaster University, Hamilton Ontario Canada, and Clinical Research Lab, Hand \\ and Upper Limb Centre, St. Joseph's Health Centre, London, Ontario, Canada \\ ${ }^{2}$ School of Physical Therapy, Western University, London, Ontario, Canada \\ ${ }^{3}$ Faculty of Health Sciences, University of Ontario Institute of Technology, Oshawa, Ontario Canada \\ ${ }^{4}$ Department of Clinical Epidemiology and Biostatistics, McMaster University, Hamilton, Ontario, Canada \\ ${ }^{5}$ School of Rehabilitation Sciences, McMaster University, Hamilton, Ontario, Canada \\ ${ }^{6}$ ICON (International Collaboration on Neck), Canada
}

\begin{abstract}
Purpose: To determine the outcome measures practice patterns in the neck pain management of various health disciplines.

Methods: A survey of 381 clinicians treating patients with neck pain was conducted.

Results: Respondents were more commonly male (54\%) and either chiropractors (44\%) or physiotherapists (32\%). The survey was international (24 countries with Canada having the largest response (44\%)). The most common assessment was a single-item pain assessment (numeric or visual analog) used by $75 \%$ of respondents. Respondents sometimes or routinely used the Neck Disability Index (49\%), the Patient Specific Functional Scale (28\%), and the Disabilities of the Arm, Shoulder and Hand (32\%). Work status was recorded in terms of time lost by more than 50\% of respondents, but standardized measures of work limitations or functional capacity testing were rarely used. The majority of respondents never used fear of movement, psychological distress, quality of life, participation measures, or global ratings of change $(<$ $10 \%$ routinely use). Use of impairment measurers was prevalent, but the type selected was variable. Quantitative sensory testing was used sometimes or routinely by $53 \%$ of respondents, whereas $26 \%$ never used it. Ratings of segmental joint mobility were commonly used to assess motion (44\% routinely use), whereas $66 \%$ of respondents never used inclinometry. Neck muscle strength, postural alignment and upper extremity coordination were assessed sometimes or routinely by a majority of respondents $(>56 \%)$. With the exception of numeric pain ratings and verbal reporting of work status, all outcomes measures were less frequently used by physicians. Years of practice did not affect practice patterns, but reimbursement did affect selection of some outcome measures.

Conclusions: Few outcome measures are routinely used to assess patients with neck pain other than a numeric pain rating scale. A comparison of practice patterns to current evidence suggessts overutilization of some measures that have questionable reliability and underutilization of some with better supporting evidence. This practice analysis suggests that there is substantial need to implement more consistent outcome measurement in practice. International consensus and better clinical measurement evidence are needed to support this.
\end{abstract}

Keywords: Survey, neck pain, outcome measure, practice patterns, profession.

\section{INTRODUCTION}

Clinical measurement is a primary driver for clinical decision-making since valid decisions depend on valid information. Tests and measures can be used to discriminate for the purposes of diagnosis, or to classify patients into meaningful subgroups. Outcome measures are used to evaluate symptoms or disability, and how either changes

*Address correspondence to this author at the School of Rehabilitation Science, IAHS, 1400 Main Street West, 4th Floor, Hamilton, ON, L8S 1C7, Canada; Tel: 905-525-9140, Ext. 22524; Fax: 905-524-0069;

E-mail: macderj@mcmaster.ca following an intervention. Valid and reliable clinical outcome measurement can support better clinical decisionmaking, quality assurance or clinical research. Outcome measures alert clinicians to the severity of a symptom or disability and so contribute to their focus of treatment intervention.

Neck disorders can cause pain [1] and impairments in: joint motion [2], sensory function [3], proprioception [4], motor function $[5,6]$, coordination, posture $[7,8]$ and balance [9]. These can be associated with functional disability $[10,11]$, loss of physical activity, loss of work capacity [12-14], psychological distress $[15,16]$, and 
impaired quality of life [17]. There are a variety of performance-based measures that can assess impairment and disability $[11,18-20]$. Impairment measures can be important to evaluate the impact of interventions on the physiological or psychological processes upon which an intervention is based and, hence, may be critical to clinical reasoning. The assessment of both impairment and disability is in keeping with the biopsychosocial view of health. Unfortunately, there is insufficient development and evaluation of measures for many of the impairments and disabilities that have been associated with neck disorders $[11,21]$.

The patient-reported perspective is important in outcome evaluation since patients usually seek treatment for relief of pain and disability. There has been extensive development of pain, disability, health status and quality-of-life patientreported outcomes (PRO) relevant to neck pain (NP). However, clinicians treating NP have a limited amount of time to administer outcome measures, and have to make decisions about the importance and priority for measures that can be used in practice. Since outcome measurement is an area where barriers to implementation are commonly reported [22-24], it is important to understand the type of measures used in practice and how this varies across professions or contexts. Therefore, the purposes of this study were:
1. To describe the utilization of PRO and impairment measures by clinicians treating NP;

2. To examine whether profession, time in practice, salary (fixed versus fee-for-service) or reimbursement source mediated the selection of outcome measures.

\section{METHODOLOGY}

A survey determined the practice patterns of clinicians providing care to patients with NP (conducted from October 2011 to August 2012). The survey was approved by the University Research Ethics Board.

\section{Survey Development and Validation}

This survey was conducted as part of a collaborative project to establish practice patterns in diagnosis, prognosis, treatment and outcome evaluation. Multiple surveys were coordinated by the individual lead investigators to address different aspects of NP management. This survey addressed outcome evaluation practices in professionals treating patients with NP.

The content of items for the survey was developed from evidence and expert clinician input (Fig. 1). Systematic reviews, narrative reviews and clinical measurement papers addressing outcome measurement in NP were reviewed to determine what measures had been studied in the literature.

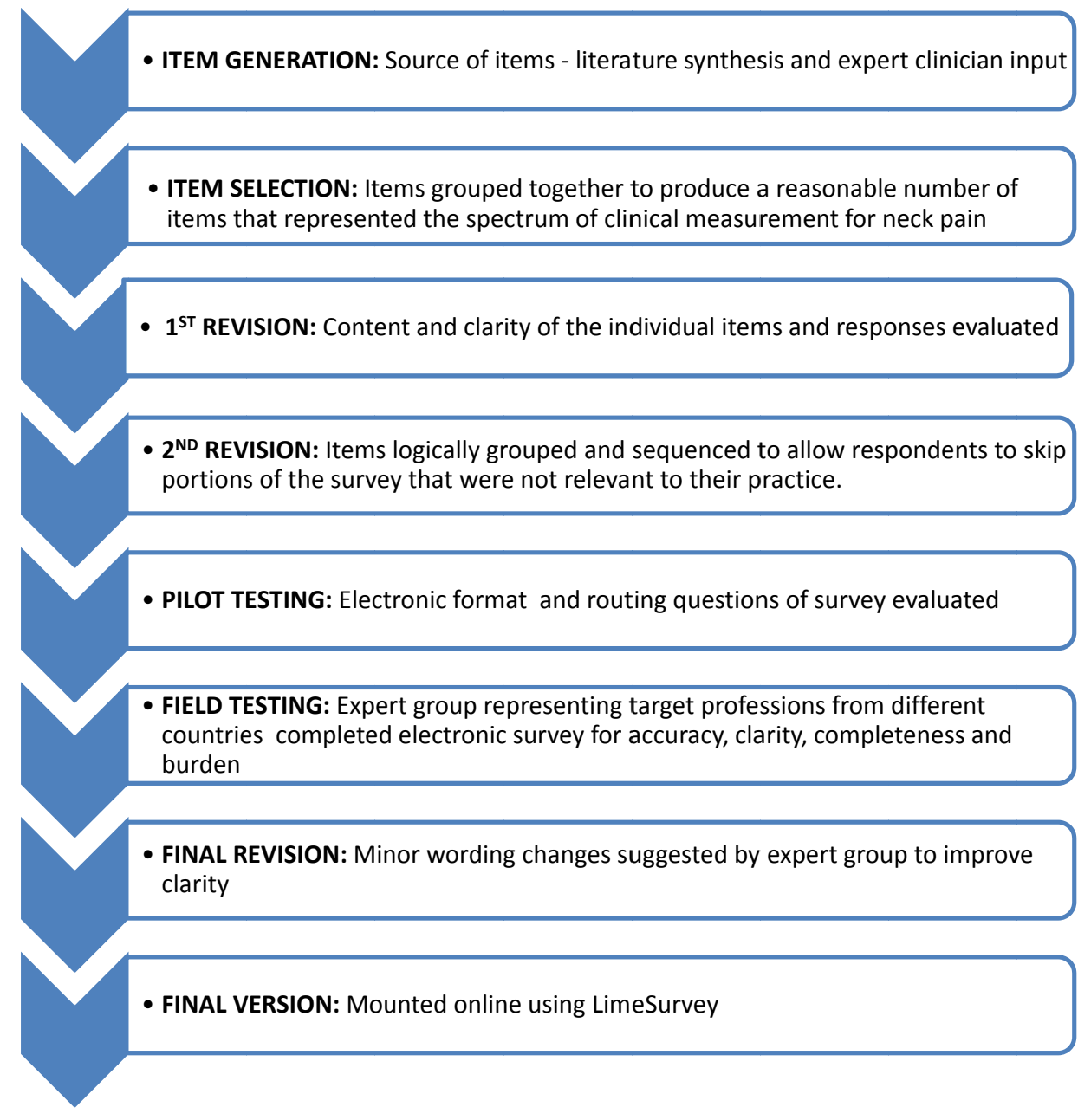

Fig. (1). Survey development process. 
The lead author generated the first wave of items from this literature synthesis, and then, with the coauthors, identified additional measures that were being used in practice through consultation. The detailed list of measures was grouped to produce a reasonable number of items that represented the spectrum of clinical measurement for NP. Item reduction was used to reduce burden. For example, there are many different sensory modalities (vibration, touch, temperature) and test instruments [25] for quantitative sensory testing, but these were grouped together to reduce response burden. The items were designed to be appropriate for different disciplines that would be sampled (physicians, psychologists, physiotherapists, massage therapists, chiropractors, and other rehabilitative professions).

Survey development was an iterative process with multiple revisions. In the first phase, item evaluation focused on the content and clarity of the individual items and responses. The second wave of revisions focused on logical grouping and sequencing of items, as well as routing questions to allow respondents to skip portions of the survey that were not relevant to their practice. Then the electronic format of the survey was piloted to evaluate electronic presentation and routing. An arms-length expert group that included all the professionals in our target audience completed the field testing. These experts reviewed the survey for accuracy, clarity, completeness and burden. Pilot results contributed to minor changes to items for clarity. The final version of the survey was mounted using LimeSurvey ${ }^{1}$, a software program for web-based survey administration

The survey was constructed to ask clinicians about their use of a variety of PRO and impairment measures. Structured response options (Never $=0 \%$ cases; Rarely $=1$ $10 \%$ cases; Sometimes $=11-70 \%$ cases; Routinely $=>70 \%$ cases) were provided for questions; an "Other" option was provided to assess whether the provided list of outcome measures was sufficiently comprehensive. Respondents were asked to rank the importance of different outcomes, as well as identify the purposes of outcome measurement in their practice. The final two sections determined demographic characteristics of the respondents and the nature of their clinical practice.

\section{Sampling Frame}

Our sampling frame included health care professional groups who were commonly involved in the management of NP, relying on both our reviews and clinical experience to identify these groups. This included physicians, physiotherapists, chiropractors, massage therapists, psychologists and other healthcare professionals. We wanted to include an international perspective and obtained international connections through the International Collaboration on Neck (ICON) members. Given that professional associations were unwilling to burden their members with mass distribution survey requests, we relied on snowball recruitment where individuals within the professions were requested to assist with contacting individuals or groups in their professional network and sending the links for the survey. Table 1 lists the professional groups who were contacted. Survey invitations were also distributed via electronic postings (e.g., e-newsletter, website, Facebook or Twitter pages).

${ }^{1}$ Lime Survey software, Survey Service \& Consulting, Hamburg, Germany.
Table 1. Sampling Frame

\begin{tabular}{|c|c|}
\hline Profession & Organization \\
\hline Chiropractors & $\begin{array}{ll}\text { - } & \text { Danish Chiropractors' Association } \\
\text { - } & \text { European Academy of Chiropractic } \\
\text { - } & \text { Netherlands Chiropractic Association } \\
\text { - } & \text { New Zealand Chiropractors' Association } \\
\text { - } & \text { Ontario Chiropractic Association }\end{array}$ \\
\hline $\begin{array}{l}\text { Manual } \\
\text { Therapists }\end{array}$ & $\begin{array}{l}\text { - Canadian Academy of Manipulative Therapy } \\
\text { - Dutch Association for Manual Therapy } \\
\text { - Finnish Association for Orthopedic Manual } \\
\text { Therapy } \\
\text { - German Manual Therapy Journal } \\
\text { - International Federation of Orthopedic } \\
\text { Manipulative Physical Therapists }\end{array}$ \\
\hline $\begin{array}{l}\text { Massage } \\
\text { Therapists }\end{array}$ & $\begin{array}{l}\text { - Massage Therapists' Association of British } \\
\text { Columbia }\end{array}$ \\
\hline Physicians & $\begin{array}{l}\text { - North American Spine Society } \\
\text { - University of British Columbia Department of } \\
\text { Family Medicine }\end{array}$ \\
\hline Physiotherapists & $\begin{array}{l}\text { - American Physical Therapy Association - } \\
\text { Orthopedic Section } \\
\text { - Canadian Physiotherapy Association - Pain } \\
\text { Sciences Division } \\
\text { - Hong Kong Physiotherapy Association } \\
\text { - Musculoskeletal Physiotherapy Australia }\end{array}$ \\
\hline $\begin{array}{l}\text { Other Healthcare } \\
\text { Profession }\end{array}$ & - Osteopathic Society of New Zealand \\
\hline
\end{tabular}

\section{Survey Administration}

It was not possible to determine how many people received our invitations. Public registration was required to participate in the survey and individuals who signed up to receive the survey link were considered "registrants". E-mail reminders were sent approximately every week to encourage completion. Response rates were calculated based on the number of people who expressed an interest in completing the survey by agreeing to receive the e-mail link for the survey and the number who completed at least part of the survey. In total, 577 people registered, and a total of 381 responses were received (estimated 66\% response rate): 357 full responses (i.e., completed $100 \%$ of survey) and 24 partial responses (i.e., completed up to $50 \%$ of survey).

After completion of registration, an email containing the survey link was sent immediately to the respondent. The identification tokens (name and e-mail address) that provided access to the survey were stored on a separate database so that the responses remained anonymous. Registrants were notified that clicking the survey link indicated that they were electronically consenting to participate. Weekly reminders were sent to registrants until they completed the survey, opted out, or received a maximum of 4 reminders. The survey took 15-20 minutes to complete.

\section{Analysis}

Descriptive statistics were used to summarize participants' responses to each question. Chi-square analyses 
were used to test for differences in the frequency of utilization of outcome measures based on experience (dichotomized), profession (chiropractic, physical therapy, medicine); income (fee for service, salary), funder (private insurance, public insurance, workers' compensation), and country (Canada, USA, Denmark).

\section{Table 2. Demographics}

\begin{tabular}{|c|c|}
\hline Years in practice since graduation (mean (sd)) & $16(11)$ \\
\hline \multicolumn{2}{|l|}{ Profession } \\
\hline Chiropractor & $44 \%$ \\
\hline Physical Therapist (Manual Therapist) & $32 \%(9 \%)$ \\
\hline Physician & $8 \%$ \\
\hline Other Profession & $6 \%$ \\
\hline \multicolumn{2}{|l|}{ Education (Highest Level Completed) } \\
\hline Diploma & $9 \%$ \\
\hline Bachelor's Degree & $15 \%$ \\
\hline Other Education & $10 \%$ \\
\hline \multicolumn{2}{|l|}{ Practice Setting } \\
\hline Private Clinic & $76 \%$ \\
\hline Rehabilitation Facility & $5 \%$ \\
\hline General Hospital & $8 \%$ \\
\hline Teaching Hospital & $7 \%$ \\
\hline Private Consultant (not clinic-based) & $6 \%$ \\
\hline Other Setting & $14 \%$ \\
\hline \multicolumn{2}{|l|}{$\%$ of Caseload that have Neck Pain } \\
\hline$<5 \%$ & $1 \%$ \\
\hline Worker's Compensation & $44 \%$ \\
\hline \multicolumn{2}{|l|}{ Salary Reimbursement Scheme } \\
\hline Fixed Salary & $26 \%$ \\
\hline Public Fee for Service & $20 \%$ \\
\hline Private Fee for Service & $68 \%$ \\
\hline \multicolumn{2}{|l|}{ Country } \\
\hline Canada & $44 \%$ \\
\hline USA & $13 \%$ \\
\hline Denmark & $13 \%$ \\
\hline New Zealand & $4 \%$ \\
\hline Australia & $3 \%$ \\
\hline Germany & $3 \%$ \\
\hline $\begin{array}{l}\text { Other (Belgium, Brazil, Finland, Hong Kong, India, Iran, Ireland, Italy, Japan, Netherlands, Norway, Portugal, Scotland, } \\
\text { South Africa, Spain, Sweden, Switzerland, United Kingdom) }\end{array}$ & $10 \%$ \\
\hline
\end{tabular}

\section{RESULTS}

Detailed demographics are listed in Table 2. Respondents $(\mathrm{n}=381)$ were more commonly male $(54 \%)$, and predominantly chiropractors $(44 \%)$ or physiotherapists $(32 \%)$. The majority of respondents worked in a private clinic and a substantial component of their practice was 
made up of patients with NP. Reimbursement was most commonly through private insurance, however, public insurance and workers' compensation were also funding sources for a substantial number of the respondents. The largest subgroup of respondents was from Canada (44\%), although 24 countries were also represented.

\section{Self-Report PRO}

Pain measures were the most routinely utilized self-report PRO (Table 3) with a numeric rating or visual analog scale the most prevalent. The numeric pain rating was the single most commonly used measure with $75 \%$ of respondents using it sometimes or routinely. Only 5\% of respondents reported using any pain scale other than the options we provided. The Pain Distress Scale was rarely used.

Physical function PRO were used less commonly than pain measures (Table 3). From the PRO that were used in practice, the Neck Disability Index (NDI) was most commonly used (49\% used it sometimes or routinely). The other two PRO with substantial use were the Disabilities of

Table 3. Utilization of Self-Report PRO

\begin{tabular}{|c|c|c|c|c|}
\hline \multirow[t]{2}{*}{ Outcome Measure } & \multicolumn{4}{|c|}{ Utilization } \\
\hline & $\begin{array}{c}\text { Routinely } \\
>70 \% \text { Cases }\end{array}$ & $\begin{array}{c}\text { Sometimes } \\
\text { 11-70\% Cases }\end{array}$ & $\begin{array}{c}\text { Rarely } \\
1-10 \% \text { Cases }\end{array}$ & $\begin{array}{c}\text { Never } \\
0 \% \text { Cases }\end{array}$ \\
\hline \multicolumn{5}{|l|}{ Pain } \\
\hline Numeric Rating Scale & $50 \%$ & $25 \%$ & $11 \%$ & $14 \%$ \\
\hline Visual Analogue Scale & $30 \%$ & $19 \%$ & $20 \%$ & $30 \%$ \\
\hline Pain Catastrophizing Scale & $3 \%$ & $7 \%$ & $20 \%$ & $69 \%$ \\
\hline Pain Distress Scale & $5 \%$ & $5 \%$ & $10 \%$ & $80 \%$ \\
\hline Other Pain Scale & $5 \%$ & $5 \%$ & $5 \%$ & $85 \%$ \\
\hline \multicolumn{5}{|l|}{ Physical Functioning } \\
\hline Neck Disability Index & $22 \%$ & $27 \%$ & $15 \%$ & $37 \%$ \\
\hline Northwick Park Neck Pain Questionnaire & $1 \%$ & $1 \%$ & $4 \%$ & $93 \%$ \\
\hline Patient Specific Functional Scale & $13 \%$ & $15 \%$ & $13 \%$ & $58 \%$ \\
\hline Disabilities of the Arm, Shoulder and Hand & $13 \%$ & $19 \%$ & $19 \%$ & $48 \%$ \\
\hline Other Disability Scales & $9 \%$ & $11 \%$ & $7 \%$ & $\mathbf{7 3 \%}$ \\
\hline \multicolumn{5}{|l|}{ Work Status } \\
\hline Time Lost from Work & $38 \%$ & $24 \%$ & $15 \%$ & $23 \%$ \\
\hline Work Limitations Scale & $13 \%$ & $14 \%$ & $13 \%$ & $\mathbf{5 9 \%}$ \\
\hline Work Distress Scale & $3 \%$ & $6 \%$ & $12 \%$ & $78 \%$ \\
\hline Other Work Scales & $3 \%$ & $0 \%$ & $1 \%$ & $95 \%$ \\
\hline \multicolumn{5}{|l|}{ Psychological Distress } \\
\hline Fear of Movement Scale & $7 \%$ & $14 \%$ & $13 \%$ & $65 \%$ \\
\hline Depression/Anxiety Scales & $5 \%$ & $11 \%$ & $21 \%$ & $62 \%$ \\
\hline Other Psychological Distress Scales & $4 \%$ & $6 \%$ & $3 \%$ & $87 \%$ \\
\hline \multicolumn{5}{|l|}{ Quality of Life } \\
\hline $\mathrm{SF}-12$ or SF-36 & $3 \%$ & $6 \%$ & $13 \%$ & $76 \%$ \\
\hline Euro-QoL & $1 \%$ & $2 \%$ & $3 \%$ & $94 \%$ \\
\hline WHO-Brief & $1 \%$ & $0 \%$ & $4 \%$ & $95 \%$ \\
\hline Other Health Status Measures & $3 \%$ & $2 \%$ & $3 \%$ & $91 \%$ \\
\hline Other Utility Measures & $3 \%$ & $0 \%$ & $1 \%$ & $95 \%$ \\
\hline \multicolumn{5}{|l|}{ Global Outcome } \\
\hline Patient Global Received Rating of Improvement or Satisfaction & $8 \%$ & $7 \%$ & $6 \%$ & $79 \%$ \\
\hline Canadian Occupational Performance Measure & $0 \%$ & $1 \%$ & $2 \%$ & $97 \%$ \\
\hline Other Participation Measures & $4 \%$ & $1 \%$ & $1 \%$ & $93 \%$ \\
\hline
\end{tabular}

Most common answer bolded 
the Arm, Shoulder and Hand (DASH) which captures upper extremity disability (32\% used it sometimes or routinely) and the Patient Specific Functional Scale (PSFS) which is designed to measure individual function (28\% used it sometimes or routinely). Work status was recorded in terms of time lost by more than $50 \%$ of respondents, although standardized measures of work limitations were rarely used.

The majority of respondents never used psychological distress measures (Table 3). Of those that did use such measures, the fear of movement scale was most commonly reported ( $21 \%$ used it sometimes or routinely). The majority of respondents never used quality-of-life measures (Table $\mathbf{3}$ ). Of those that did use such measures, the most commonly reported one was the SF-12/SF-36 (3\% routinely use). More than $90 \%$ of respondents never used measures of participation (Canadian Occupational Performance Measure). A patient global rating of improvement or satisfaction was used routinely by only $8 \%$ of respondents.

\section{Impairment Performance-Based Outcome Measures}

Impairments were measured by a majority of respondents, but the choices were variable across participants (Table 4). Quantitative sensory testing (QST) (e.g., vibrometry, touch, temperature) was used sometimes or routinely by $53 \%$ of respondents, whereas $26 \%$ never used it. Assessment of neck motion indicated that four types of joint motion assessments were used by a subset of respondents. Ratings of segmental joint mobility were the most commonly selected mobility measure (44\% routinely use), whereas inclinometry was the least used technique (66\% never used). Neck muscle strength, postural alignment and upper extremity coordination were assessed sometimes or routinely by a majority of respondents ( $>56 \%)$. Of these, posture was most routinely used (40\%). The muscle impairment that was least assessed was neck muscle endurance (32\% never performed testing). A majority of respondents never used functional performance tests. The survey responses did not capture all functional performance tests, as $11 \%$ of respondents reported that they routinely used a physical or functional measure that was not listed in the survey.

\section{Ranking and Reasons for Use of Outcome Measures}

In ranking the importance of different outcomes achieved with treatment, pain relief was most highly ranked by respondents (Table 5), whereas coping with residual pain and disability received the lowest rank. The reasons for using outcome measures were diverse (Table 6). Marketing and research were least endorsed as reasons for using outcome measures. Charting, setting goals, and communicating with patients were most endorsed ( $40 \%$ to $42 \%$ ).

\section{Years of Practice and Reimbursement and Selection of Outcome Measures}

There was no difference in the mean years of practice for users (routinely and sometime use) versus non-users (rarely and never use) for most of the outcome measures (Table 7). The exceptions were the pain catastrophizing scale and the PSFS where users were about 3 years older than non-users. There were differences in outcome measure utilization with a trend for salaried clinicians to collect more outcome measures (Table 8) and across health care systems (Table 9) with a number of measures used more in the workers' compensation system.

Table 4. Utilization of Performance-Based Outcome Measures

\begin{tabular}{|c|c|c|c|c|c|}
\hline Impairment & Outcome Measure & \multicolumn{4}{|c|}{ Utilization } \\
\hline \multirow{2}{*}{ Pain Threshold Perception } & Quantitative Sensory Tests & $23 \%$ & $30 \%$ & $21 \%$ & $26 \%$ \\
\hline & Pain Algometry & $11 \%$ & $15 \%$ & $16 \%$ & $57 \%$ \\
\hline \multirow{2}{*}{ Motion } & Inclinometry of Neck Motion & $9 \%$ & $13 \%$ & $12 \%$ & $66 \%$ \\
\hline & Movement Diagram & $31 \%$ & $15 \%$ & $12 \%$ & $41 \%$ \\
\hline \multirow{2}{*}{ Muscle Function } & Neck Muscle Strength & $32 \%$ & $32 \%$ & $24 \%$ & $12 \%$ \\
\hline & Physical Fitness & $2 \%$ & $6 \%$ & $17 \%$ & $75 \%$ \\
\hline \multirow{3}{*}{ Functional Performance } & Functional Performance Test & $12 \%$ & $19 \%$ & $16 \%$ & $52 \%$ \\
\hline & Functional Capacity Assessment & $7 \%$ & $13 \%$ & $23 \%$ & $56 \%$ \\
\hline & Proprioception Test & $11 \%$ & $28 \%$ & $32 \%$ & $29 \%$ \\
\hline Not classified & Other Physical or Functional Measures & $11 \%$ & $6 \%$ & $4 \%$ & $78 \%$ \\
\hline
\end{tabular}

Most common answer bolded. 
Table 5. Mean Rank of Importance for Different Outcomes Achieved with Treatment

\begin{tabular}{|l|c|}
\hline \multicolumn{1}{|c|}{ Outcome } & \multicolumn{1}{|c|}{$\begin{array}{c}\text { Mean Rank } \\
\text { (1 = Most Important, } \\
\text { 7 = Least Important })\end{array}$} \\
\hline \hline Pain Relief & $\mathbf{1 . 9}$ \\
\hline Patient Satisfaction & 3.6 \\
\hline Reduce Physical Impairments & 3.7 \\
\hline Return to Work & 3.9 \\
\hline Normalize Participation in Life Roles & 4.0 \\
\hline Normalize Physical Performance & 4.1 \\
\hline Coping with Residual Pain and Disability & 5.1 \\
\hline Highest ranking bolded. &
\end{tabular}

When comparing the most common health professions represented (Table 10), the one measure that showed the most consistent use across professions was the numeric pain rating scale. For almost all other outcome measures, physical therapists and chiropractors used outcome measures more than physicians (Figs. 2-6, Table 10). Physical therapists used the following measure more than chiropractors: the NDI, the PSFS, movement diagrams, segmental mobility, neck muscle strength and postural alignment $(\mathrm{p}<0.05)$. Chiropractors used the following measures more than physical therapists: QST ( $\mathrm{p}<0.05)$.

\section{Countries and Use of Outcome Measures}

When comparing the top 3 represented countries (Canada, USA, Denmark), there were significant differences in routine utilization of the most common outcome measures (Table 11): numeric ratings scale, ratings of segmental joint mobility, postural alignment measures, time lost from work, neck muscle strength, movement diagram, visual analog scale, NDI $(\mathrm{p}<0.05)$.

\section{DISCUSSION}

This survey suggests that other than pain, there is little consistency amongst clinicians treating patients with NP with respect to which outcome measures should be used. Consistent use of a core set of outcome measures can be valuable in practice as standardized data can inform decision-making. Further, qualitative studies in patients [26, 27] with NP indicate that having their clinician take regular measurements enhances patient understanding of the variations in their NP, and contributes to their commitment to maintain their exercise programs [27]. Since patient communication and setting treatment goals were more common reasons reported for using outcome measures, it appears that clinicians and patients are aligned with reasons for using outcome measures. This alignment suggests a mechanism by which outcome measurement might contribute to improved outcomes-through better adherence and goal-setting.

Since the most commonly used measure is the numeric pain rating scale which is a single item that can be verbally administered, it is possible that clinicians who use it may not have gone through the process of "setting up" for questionnaires that are multi-item PRO. Multi-item PRO would require either paper or electronic completion and scoring, and, thus, may be seen as more intrusive. Outcome measures that can be verbally administered during the patient interaction have advantages in that they may be easily incorporated into the clinical interaction. However, a disadvantage is that they provide a limited scope of information, may be less reliable and sensitive to picking up changes in the patient's condition [28], and may be more prone to reporting bias when they are administered by the healthcare provider.

Of the multi-item PRO, respondents most commonly used the NDI. This is consistent with the largest volume of neck-related clinical measurement evidence supporting the NDI reported in evidence syntheses, and the fact that the NDI is the most commonly used PRO in clinical research $[11,29]$. A systematic review of neck-specific PRO found 5 scales with similar characteristics $[9,30,31]$. The NDI has

Table 6. Reasons for Using Outcome Measures

\begin{tabular}{|c|c|c|c|c|}
\hline Reason for Use & \multicolumn{4}{|c|}{ Utilization } \\
\hline Fulfilling Charting/Documentation & $42 \%$ & $23 \%$ & $13 \%$ & $18 \%$ \\
\hline Medicolegal Documentation Requirements & $36 \%$ & $21 \%$ & $20 \%$ & $19 \%$ \\
\hline Setting Treatment Goals & $41 \%$ & $30 \%$ & $12 \%$ & $12 \%$ \\
\hline Communicating with Patients & $40 \%$ & $29 \%$ & $14 \%$ & $11 \%$ \\
\hline Communicating with funders & $19 \%$ & $23 \%$ & $18 \%$ & $34 \%$ \\
\hline Communicating with other health professionals & $21 \%$ & $37 \%$ & $21 \%$ & $16 \%$ \\
\hline Program evaluation/quality assurance & $19 \%$ & $26 \%$ & $21 \%$ & $29 \%$ \\
\hline
\end{tabular}


shown excellent clinical measurement properties across multiple studies as was highlighted on a systematic review of those properties [11]. This review also found that not all studies agree about the measurement properties that are acceptable. There have been concerns about factor structure of the NDI [32,33] and certain items, e.g., driving, have been considered problematic as they exhibit a high rate of missingness since they do not always apply to all patients [11].

The nature of our survey does not allow us to explore reasons why people chose specific instruments. However, it is notable that the two PRO used most (after the NDI) were PRO that allow reporting on dimensions that are not included on the NDI. Both the DASH [34] and the PSFS [3538] have been validated for neck disorders which supports their uptake in clinical practice. The DASH measures upper extremity function. The items of the DASH are rated as equally problematic as the items of the NDI by patients with NP [34], highlighting the extent that the upper limb is impaired by neck disorders. Thus, use of the DASH in NP has both conceptual and empirical support. The PSFS captures functional disability on items selected by the individual providing a patient-centered approach to evaluation. An additional benefit of focusing on items
Table 7. Mean Years of Practice of Users vs Non-Users of Selected Outcome Measures

\begin{tabular}{|l|c|c|}
\hline \multirow{2}{*}{\multicolumn{1}{|c|}{ Outcome Measure }} & Non-User & User \\
\cline { 2 - 3 } & $\begin{array}{c}\text { Mean Years } \\
\text { of Practice }\end{array}$ & $\begin{array}{c}\text { Mean Years } \\
\text { of Practice }\end{array}$ \\
\hline \hline Numeric Rating Scale & 17.7 & 16.2 \\
\hline Pain Catastrophizing Scale & $\mathbf{1 5 . 3} *$ & $\mathbf{1 8 . 7}$ \\
\hline Neck Disability Index & 16.0 & 16.6 \\
\hline Patient Specific Functional Scale & $\mathbf{1 5 . 2 *}$ & $\mathbf{1 8 . 0}$ \\
\hline Disabilities of the Arm, Shoulder and Hand & 16.7 & 16.1 \\
\hline Work Limitations Scale & 15.7 & 17.5 \\
\hline Depression/Anxiety Scales & 15.7 & 17.3 \\
\hline Pain Algometry & 15.9 & 17.0 \\
\hline Quantitative Sensory Tests & 17.5 & 16.0 \\
\hline Goniometric Measures of Neck Motion & 15.2 & 17.3 \\
\hline Movement Diagram & 16.0 & 16.6 \\
\hline Ratings of Segmental Joint Mobility & 16.8 & 16.2 \\
\hline Upper Extremity Muscle Coordination & 17.4 & 16.1 \\
\hline Postural Alignment Measures & 17.2 & 16.2 \\
\hline
\end{tabular}

Table 8. Utilization of Common Outcome Measures by Reimbursement Category

\begin{tabular}{|c|c|c|}
\hline Outcome Measure & \multicolumn{2}{|c|}{ Users (\% Within Salary Scheme) } \\
\hline Numeric Rating Scale & $65 \% *$ & $46 \% *$ \\
\hline \multicolumn{3}{|l|}{ Physical Functioning } \\
\hline Patient Specific Functional Scale & $31 \% *$ & $29 \% *$ \\
\hline DASH & $44 \% *$ & $28 \% *$ \\
\hline \multicolumn{3}{|l|}{ Work Status } \\
\hline Time Lost from Work & $67 \%$ & $59 \%$ \\
\hline SF-12 or SF-36 & $20 \% *$ & $5 \% *$ \\
\hline \multicolumn{3}{|l|}{ Global Outcome } \\
\hline Patient Global Received Rating of Improvement or Satisfaction & $20 \%$ & $14 \%$ \\
\hline \multicolumn{3}{|l|}{ Physical Impairment } \\
\hline Quantitative Sensory Tests & $52 \%$ & $51 \%$ \\
\hline Ratings of Segmental Joint Mobility & $69 \%$ & $65 \%$ \\
\hline Neck Muscle Strength & $69 \%$ & $62 \%$ \\
\hline Postural Alignment Measures & $67 \%$ & $66 \%$ \\
\hline
\end{tabular}

*Significant Difference $(\mathrm{p}<0.05)$ bolded 


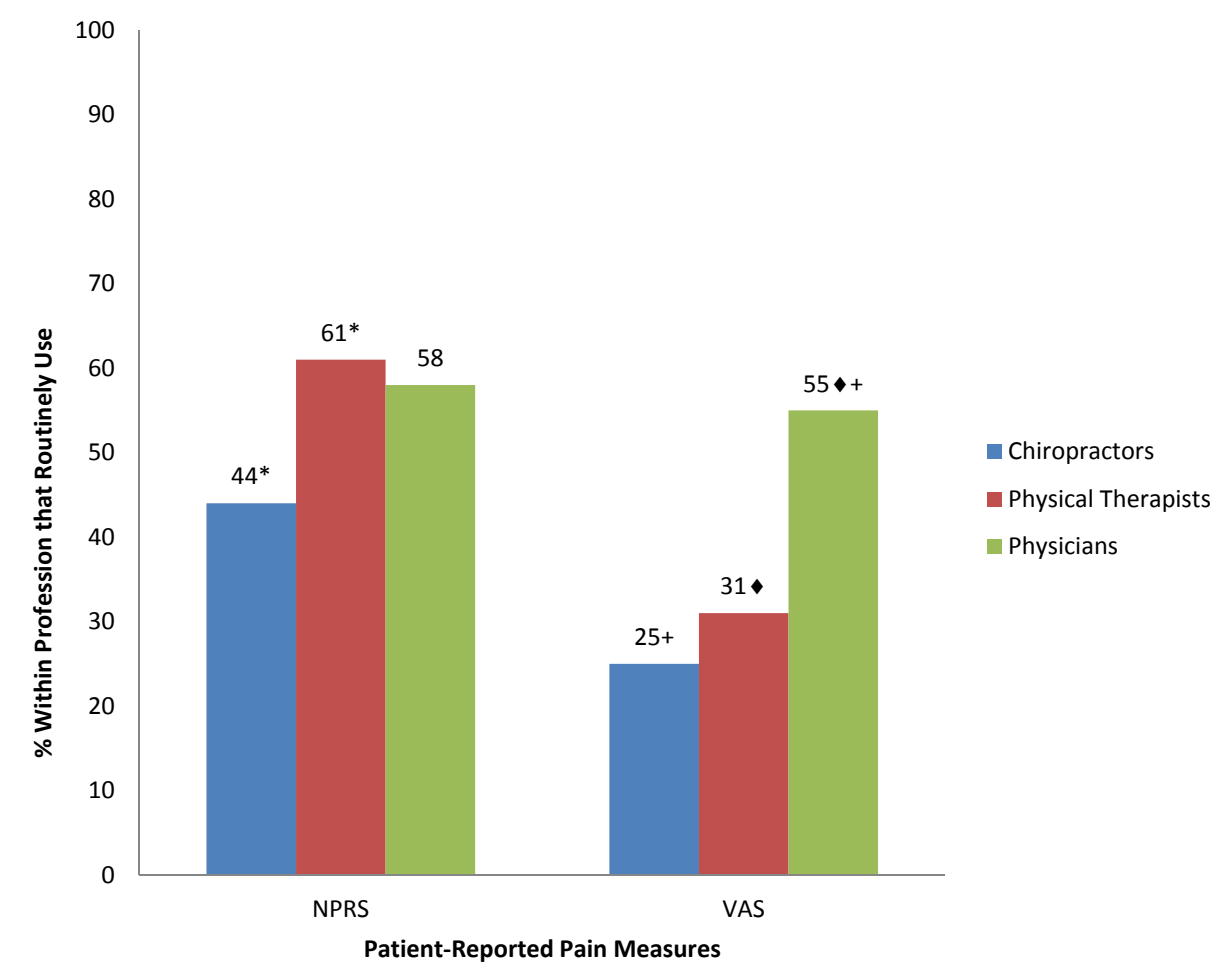

*Significant Difference $(p<0.05)$ between chiropractors and physical therapists +Significant Difference $(p<0.05)$ between chiropractors and physicians

- Significant Difference $(p<0.05)$ between physical therapists and physicians NPRS $=$ Numeric Pain Rating Scale, VAS $=$ Visual Analogue Scale

Fig. (2). Differences in use of patient-reported pain measures across professions.

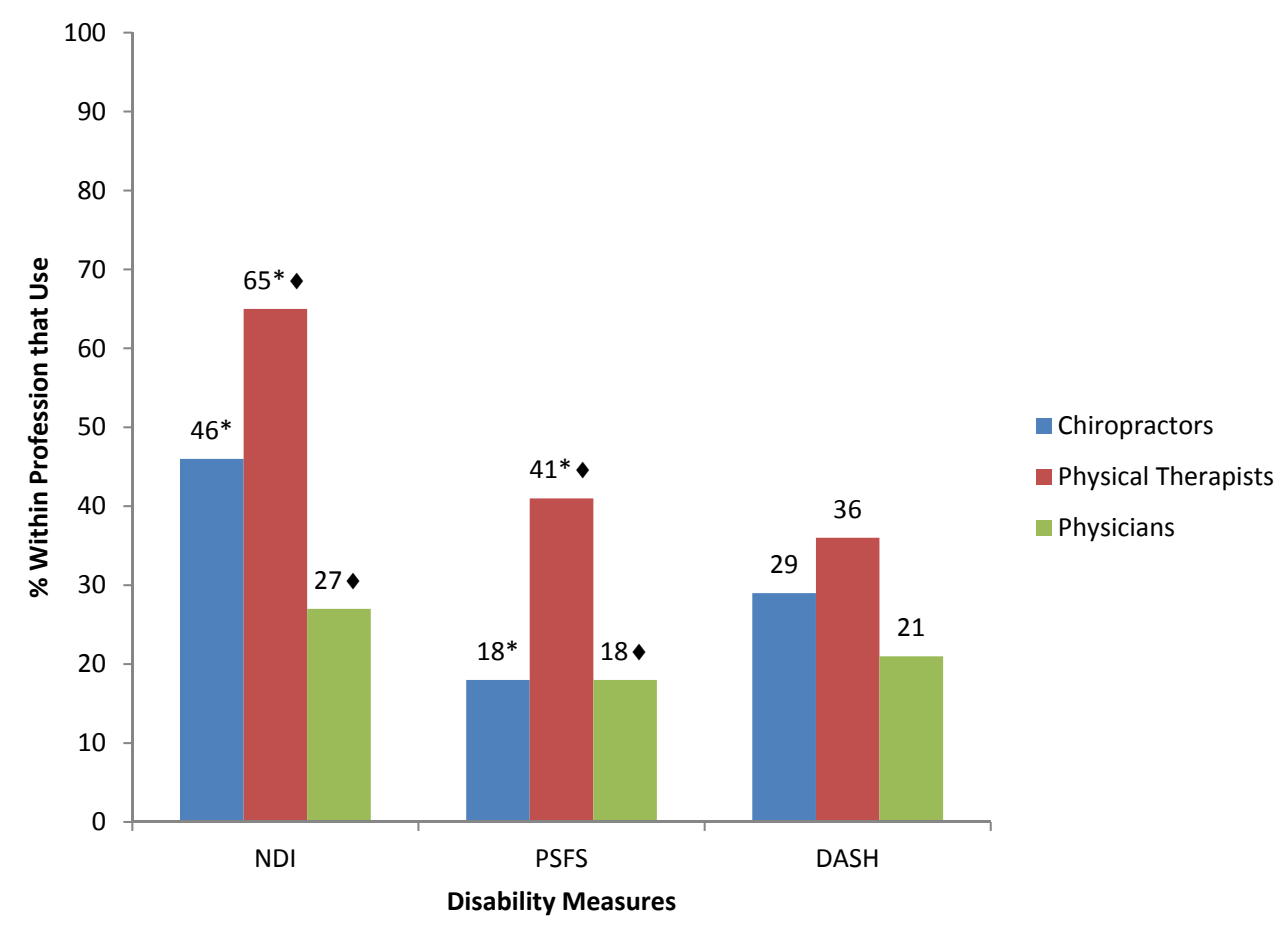

*Significant Difference $(p<0.05)$ between chiropractors and physical therapists - Significant Difference $(p<0.05)$ between physical therapists and physicians $\mathrm{NDI}=$ Neck Disability Index, PSFS = Patient Specific Functional Scale, DASH = Disabilities of the Arm, Shoulder, Hand

Fig. (3). Difference in use of disability measures across professions. 


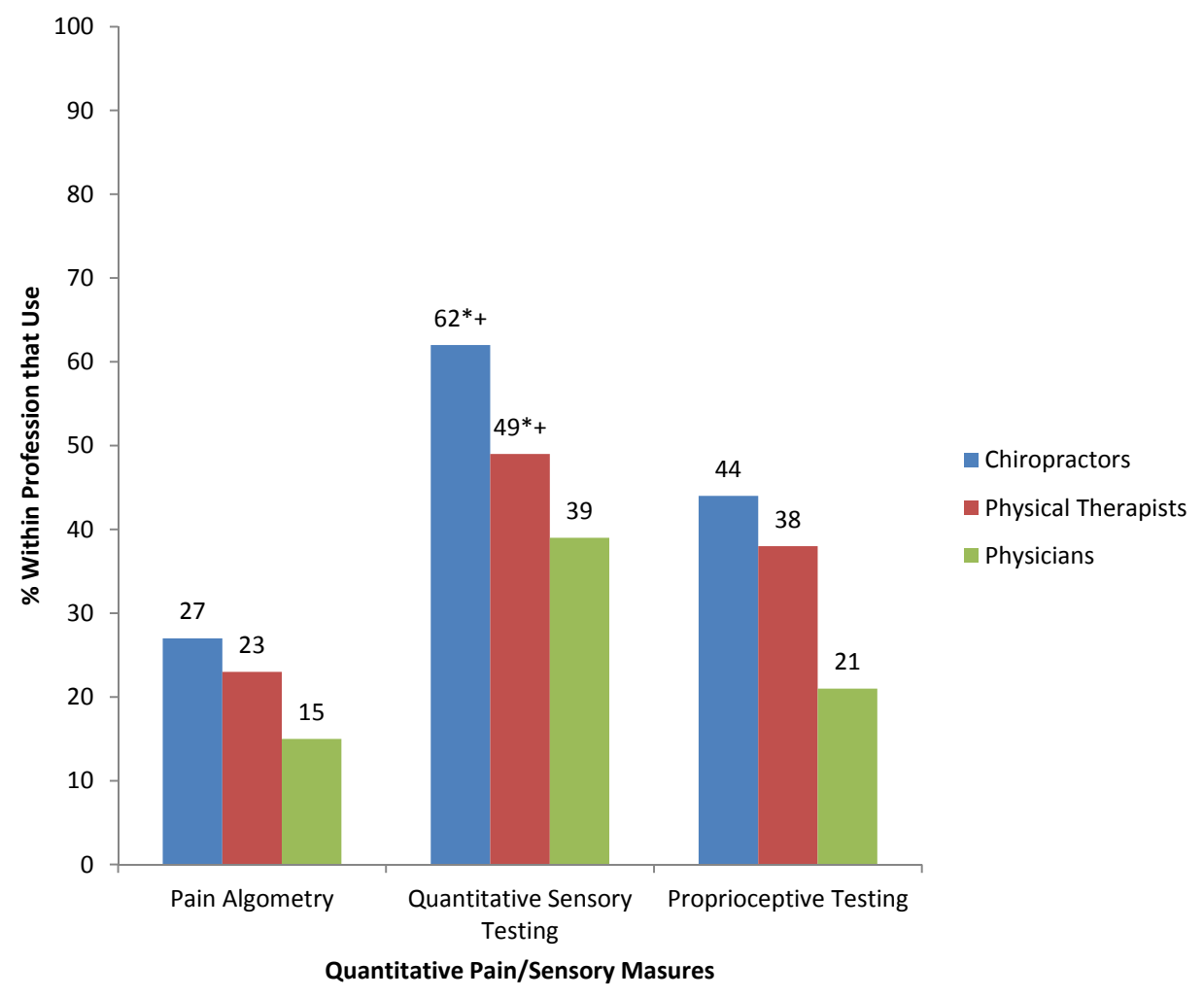

*Significant Difference $(p<0.05)$ between chiropractors and physical therapists +Significant Difference $(p<0.05)$ between chiropractors and physicians

Fig. (4). Difference in use of quantitative pain/sensory measures across professions.

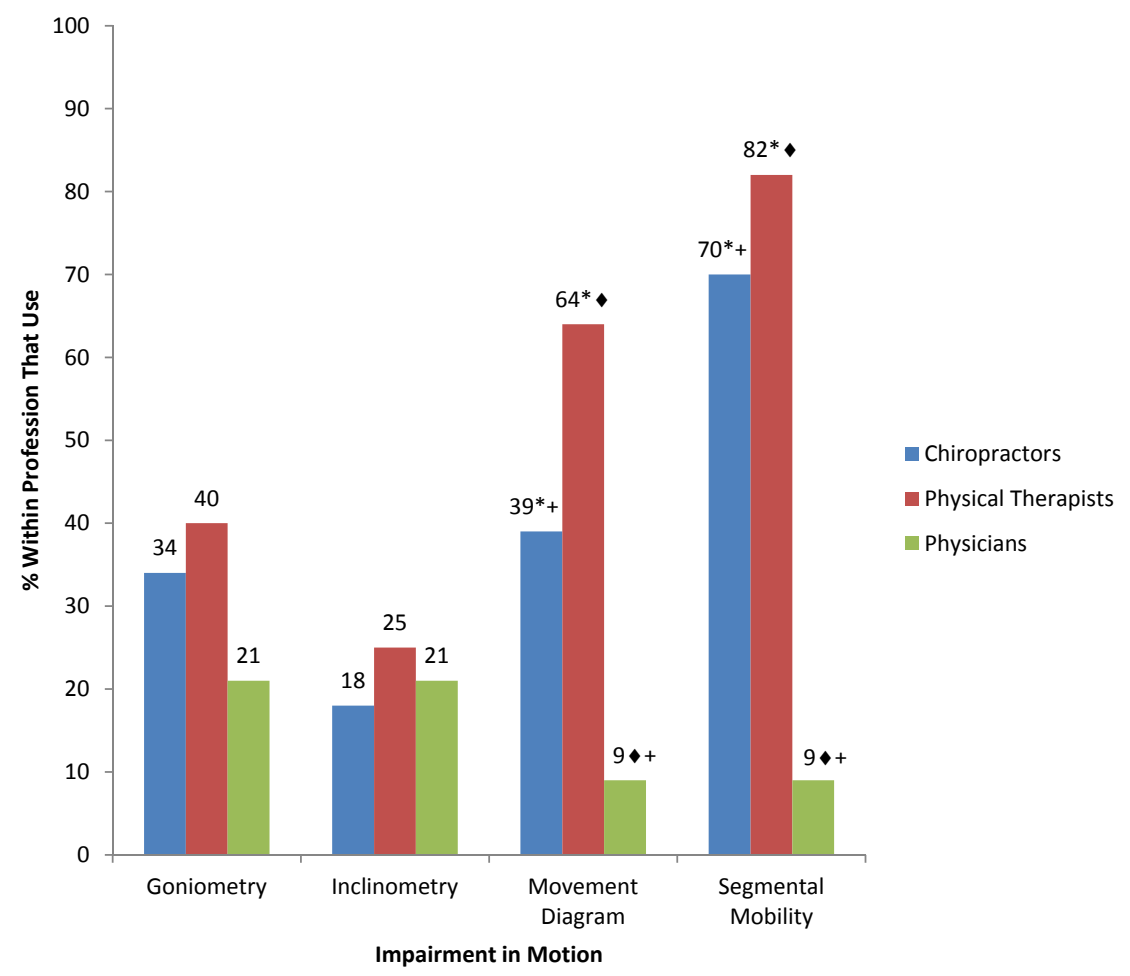

*Significant Difference $(p<0.05)$ between chiropractors and physical therapists +Significant Difference $(p<0.05)$ between chiropractors and physicians

- Significant Difference $(p<0.05)$ between physical therapists and physicians

Fig. (5). Difference in use of impairment in motion across professions. 


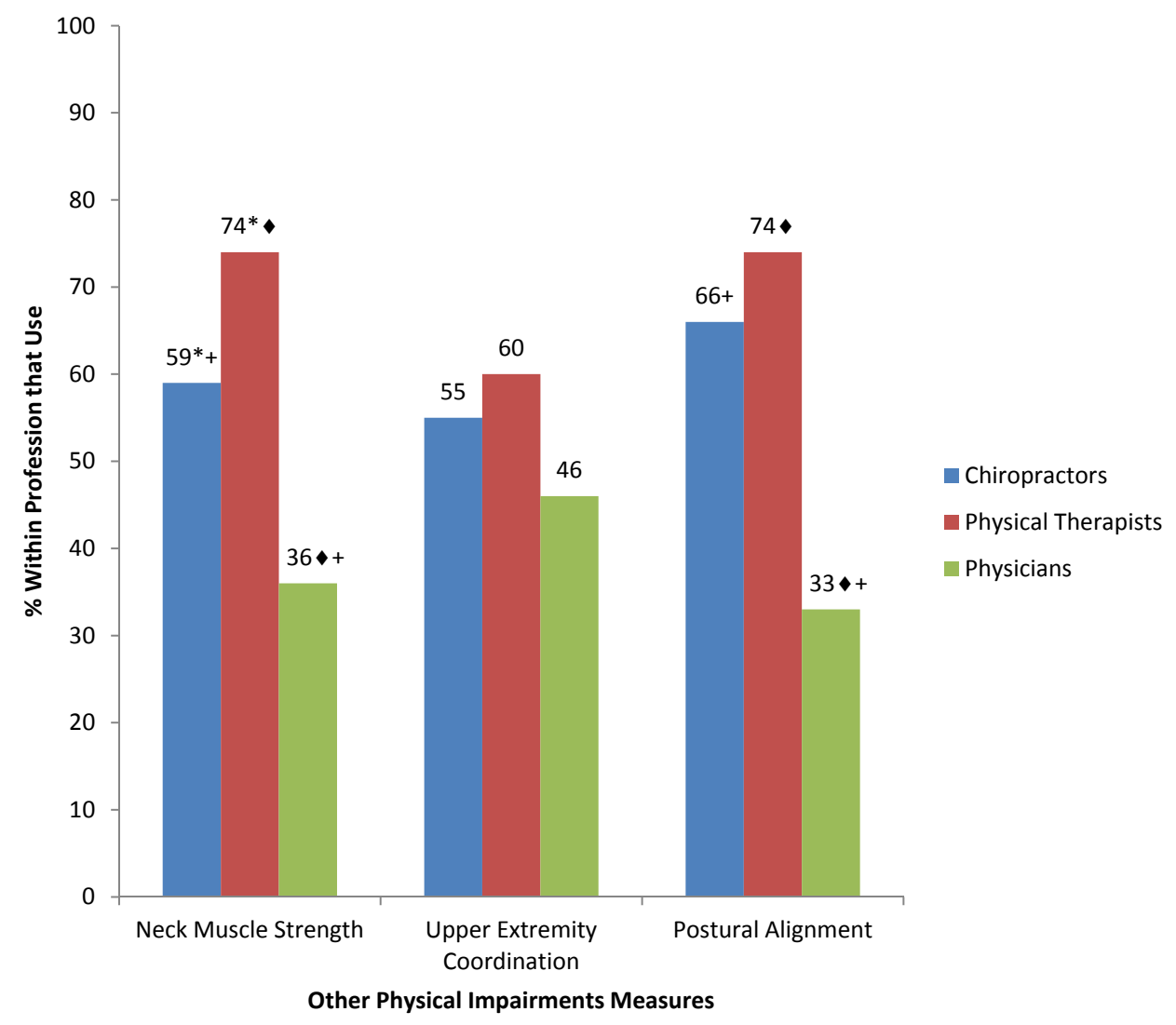

*Significant Difference $(p<0.05)$ between chiropractors and physical therapists

+Significant Difference $(p<0.05)$ between chiropractors and physicians

- Significant Difference $(p<0.05)$ between physical therapists and physicians

Fig. (6). Difference in use of other impairment measures across professions.

selected by the patient is that this supports higher responsiveness than the NDI [39]. However, since the items are not consistent across patients, absolute scores cannot be compared between patients. Although the use of PRO in clinical research is now well accepted and clinical trials often include one as the primary outcome measure, it appears that utilization in managing NP lags well behind research utilization. This is consistent with the observations in other musculoskeletal conditions such as distal radius fracture [40]. Comparative studies have not clearly established one PRO to be superior to others for NP, so the practice patterns may reflect the need for more comprehensive and consistent clinical measurement evidence and a greater focus on knowledge translation to move these tools into practice. Previous surveys of outcome measure ultilization suggested cervical and back pain were areas where outcome measurement is most practiced [22], suggesting that broad knowledge translation strategies are needed to increase the use of outcome measures for musculoskeletal conditions.

The variation in measurement of physical impairments indicates substantial diversity in practice patterns. Measures that were commonly used were segmental mobility and postural assessment. Posture has been supported as a contributor to NP in some studies [8, 41-43]. However, clinical measurement studies have not been supportive [4446] and a systematic review concluded that there was insufficient evidence to determine whether forward head posture, head extension, side-flexion or rotation differ between people with or without NP [47]. The findings from a systematic review of inter-examiner reliability of passive assessment of segmental intervertebral motion in the cervical and lumbar spine [20] found low inter-rater reliability. Conversely, another systematic review suggested that the CROM device and the single inclinometer were reliable instruments for measuring active range of motion in patients with non-specific NP. The evidence for the reliability of CROM measures is strong, although validity and responsiveness have been less well documented [18]. Respondents in this survey preferred clinician-based, handson assessments of joint motion rather than instrumented measurements, despite the fact that the evidence supports the latter. This is in contrast to peripheral joints where goniometry is routinely used [40] and indicates a gap between evidence and practice.

Neck muscle strength was routinely assessed by $1 / 3$ of respondents and sometimes used by another $1 / 3$ of respondents. We did not collect information about reasons for selecting this measure, instruments used, measurement techniques or types of muscle actions that were assessed. We know that that there is a wide range of potential strength test protocols. Devices that might be used to assess strength include: manual, hand-held dynamometers, isokinetic dynamometers and neck-specific strength testing equipment. A systematic review of muscle functioning in non-specific 
Table 9. Utilization of Common Outcome Measures by Healthcare System

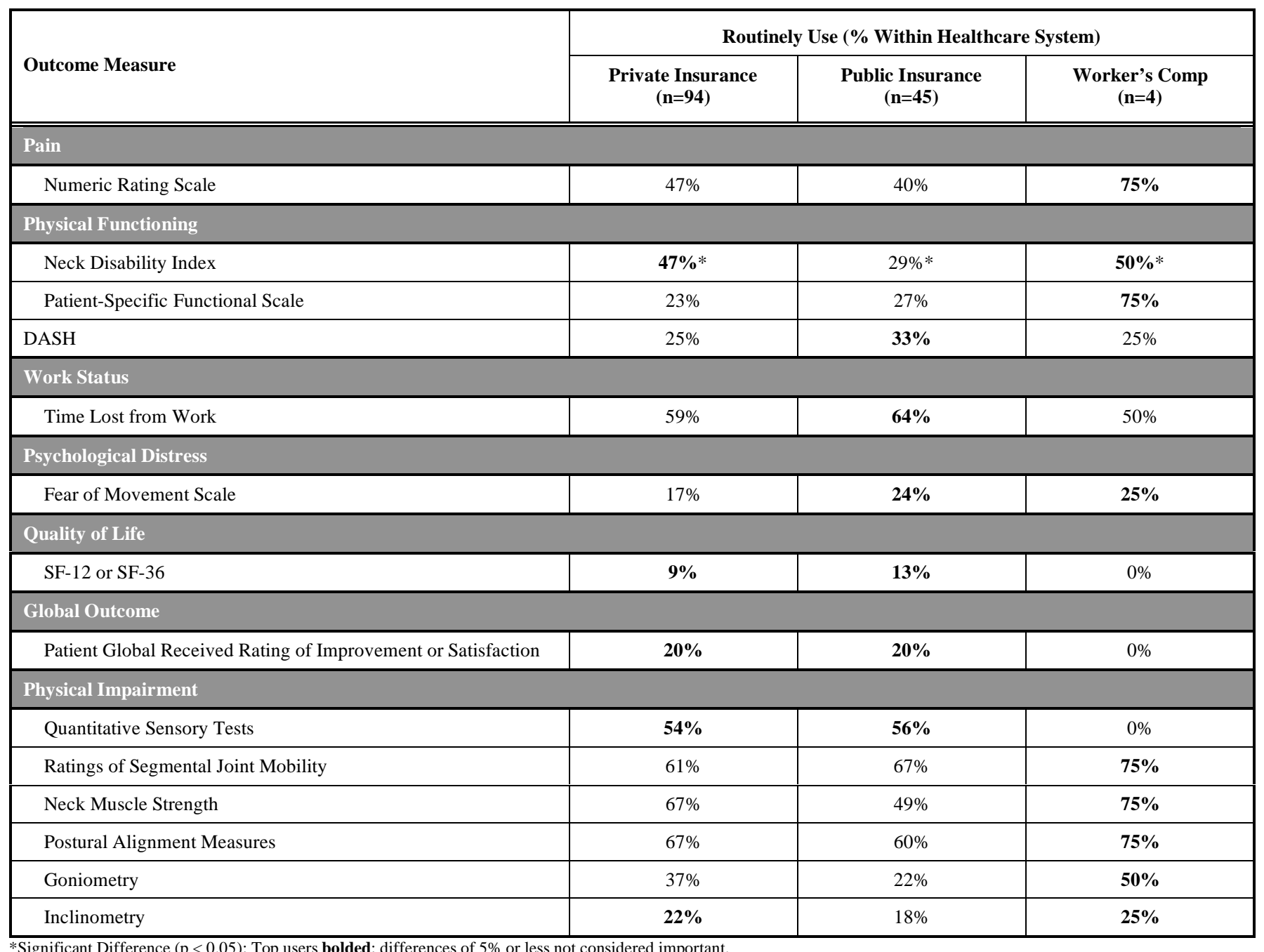

NP found 16 studies that spanned different techniques including the craniocervical flexion tests, manual muscle testing, functional lift test, a timed weighted overhead test, a cervical progressive iso-inertial lifting evaluation (PILE) test and endurance tests for short neck flexors [18]. Due to limitations in the evidence, only the latter had sufficient supporting evidence of reliability. Since muscle strength training is effective [48] in managing neck disorders, strength of the neck muscles is a valid construct to be assessed as an outcome measure that would monitor the impact of strengthening programs. Failure to assess initial muscle strength may result in missing the deficits that would identify specific patients and would benefit from neck muscle strengthening. Failure to have ongoing assessment of strength would be a barrier to tailoring the program to optimize outcomes. At this time, neither evidence nor consensus from clinical practice can be used to establish best practice in outcome measurement of muscle function in patients with NP.

QST was used sometimes or routinely by more than $50 \%$ of respondents. This was greater utilization than expected given that information about the importance of QST $[49,50]$ is relatively recent, and because it requires equipment that may not be routinely available in clinical practices. We cannot be confident how this item was interpreted since QST can encompass a range of tests. Pain threshold testing using pressure devices has been recently introduced into practice, with established reliability $[51,52]$ and it has been shown to be predictive of outcomes. The low rates of pain threshold testing reflected in this survey indicate a need to translate this assessment knowledge into practice. Although the responsiveness of sensory measures to detect change has been studied in peripheral neuropathy [53-55], it is less well known whether these measures detect change in response to treatment of neck conditions suggesting the need for additional research.

Pain relief was the predominant goal of intervention so it was appropriate that it was the most commonly measured concept. Our survey included mostly clinicians who are trained to focus on the physical aspects of health problems. It included few psychologists and we might expect different responses patterns in this discipline since their primary focus would be psychological. Since pain relief was ranked highest, this may reflect that clinicians hope to eradicate pain and avoid the need to focus on coping with residual pain and disability. Few respondents measured psychological aspects of pain, suggesting that their ability to detect and respond to psychological symptoms or poor coping strategies is limited. 
Table 10. Utilization of Common Outcome Measures by Professions

\begin{tabular}{|c|c|c|c|}
\hline Numeric Rating Scale & $61 \% *$ & $44 \% *$ & $58 \% *$ \\
\hline \multicolumn{4}{|l|}{ Physical Functioning } \\
\hline DASH & $36 \%$ & $29 \%$ & $21 \%$ \\
\hline \multicolumn{4}{|l|}{ Work Status } \\
\hline Time Lost from Work & $59 \%$ & $67 \%$ & $64 \%$ \\
\hline \multicolumn{4}{|l|}{ Psychological Distress } \\
\hline SF-12 or SF-36 & $9 \% *$ & $5 \% *$ & $27 \% *$ \\
\hline \multicolumn{4}{|l|}{ Global Outcome } \\
\hline Patient Global Received Rating of Improvement or Satisfaction & $19 \%$ & $16 \%$ & $6 \%$ \\
\hline \multicolumn{4}{|l|}{ Physical Impairment } \\
\hline Quantitative Sensory Tests & $49 \% *$ & $62 \% *$ & $39 \% *$ \\
\hline Ratings of Segmental Joint Mobility & $82 \% *$ & $70 \% *$ & $9 \% *$ \\
\hline Neck Muscle Strength & $74 \% *$ & $59 \% *$ & $36 \% *$ \\
\hline Postural Alignment Measures & $74 \% *$ & $66 \% *$ & $33 \% *$ \\
\hline Goniometry & $40 \%$ & $34 \%$ & $21 \%$ \\
\hline
\end{tabular}

Although coping with residual pain and disability was ranked the lowest, this does not necessarily mean it is not considered in treatment planning. Since residual pain episodes are the classic pattern of NP, clinicians may apply this evidence in their treatment approach. However, the low focus on psychological aspects of NP implies that more attention on psychological distress and coping strategies is needed. Qualitative studies suggest that patients want and value attention to the psychosocial aspects of NP [56].

We expected that physicians might use standardized outcome measures less than chiropractors or physical therapists, simply based on the amount of time spent with patients. This was true for all measures, except single-item pain ratings which can be expedient when verbally administered using a 0-10 scale. Chiropractors and physical therapists were more similar in terms of outcome usage across many of the constructs. Physical therapists were more likely to use a number of measures, including PRO, motion, posture and muscle measures. Chiropractors were more likely to report usage of QST. These differences may reflect differences in training or focus.

Setting also influenced outcome measures use. In general, salaried clinicians used outcome measures more than fee-for-service clinicians. This may reflect time
Table 11. Utilization of Common Outcome Measures by Country

\begin{tabular}{|l|c|c|c|}
\hline \multirow{2}{*}{ Outcome Measure } & \multicolumn{3}{c|}{$\begin{array}{c}\text { Routinely Use } \\
\text { Within Country })\end{array}$} \\
\cline { 2 - 4 } & $\begin{array}{c}\text { Canada } \\
(\mathbf{n = 1 6 6})\end{array}$ & $\begin{array}{c}\text { USA } \\
(\mathbf{n = 5 0})\end{array}$ & $\begin{array}{c}\text { Denmark } \\
(\mathbf{n = 4 8})\end{array}$ \\
\hline \hline Numeric Ratings Scale & $53 \% *$ & $\mathbf{7 0 \%} *$ & $31 \% *$ \\
\hline Ratings of Segmental Joint Mobility & $45 \% *$ & $24 \% *$ & $\mathbf{5 2 \%}$ \\
\hline Postural Alignment Measures & $\mathbf{4 7 \% *}$ & $22 \% *$ & $17 \% *$ \\
\hline Time Lost From Work & $30 \% *$ & $34 \% *$ & $\mathbf{5 8 \% *}$ \\
\hline Neck Muscle Strength & $\mathbf{3 7 \%} *$ & $30 \% *$ & $15 \% *$ \\
\hline Movement Diagram & $\mathbf{4 2 \% *}$ & $12 \% *$ & $23 \% *$ \\
\hline Visual Analogue Scale & $27 \% *$ & $\mathbf{3 8 \% *}$ & $13 \% *$ \\
\hline NDI & $\mathbf{3 0 \% *}$ & $28 \% *$ & $6 \% *$ \\
\hline
\end{tabular}

*Significant Difference $(\mathrm{p}<0.05)$; Top users bolded.

priorization since fee-for-service clinicians may find that administration of outcome measures takes too much time and interferes with efficient patient flow. Some outcome 
measures were used more commonly in workers' compensation context. This may reflect that outcome measures are more mandated by the insurer or a need to use outcome measures to approve or justify treatment. Since this survey was international, the health care system factors may have varied by country, payor and profession. In fact, our analyses across the 3 countries (Canada, USA, Denmark) with the highest response rates showed there were differences in these countries' use of the more common outcome measures.

This study established current practices in outcome evaluation in different professions treating NP. This study should be interpreted with consideration to its limitations. The sampling approach meant that we could not estimate our true response rate. Further, although we sampled internationally, we had a large percentage of Canadian respondents, so our results may not adequately represent other countries. Since the research team originated in Canada, this likely reflects our sampling approach which was dependent on a champion within a network. In addition, we were not able to obtain sufficient numbers of all the professional subgroups we intended to sample. Lastly, we cannot be confident how items were interpreted and whether test names were interpreted in the same way across different respondents.

The lack of consensus on PRO and impairment suggests that a consensus approach to establishing a core set of measures would be valuable. However, many areas of NP assessment require further research to develop optimal tests and measures. Further evidence about the clinical measurement properties of tests across different subtypes of NP and contexts is needed before a consensus exercise could be fueled by adequate evidence to specify the best measures. However, agreement on core concepts might direct future measurement studies to focus on developing optimal measures and evidence across all important domains of impairment and disability related to NP.

\section{CONCLUSION}

The findings of our international, multidisciplinary survey suggest that with the exception of pain ratings, no other outcome measures are consistently used by clinicians who manage NP. Variations by profession, country, service model exist, but do not alter the conclusion that there is poor integration of standardized outcome measurement into management of NP. This analysis suggests a need for further research providing better clinical measurement evidence, as well as international consensus to define core concepts and related outcome measures in the treatment of neck disorders.

\section{CONFLICT OF INTEREST}

The authors confirm that this article content has no conflict of interest.

\section{ACKNOWLEDGEMENTS}

ICON is a multi-disciplinary collaborative group that includes scientist-authors (listed below) and support staff (Margaret Lomotan) that conduct knowledge synthesis and translation aimed at reducing the burden of neck pain.

The ICON authors provided direction of the project; input into the survey questions and review of the findings/manuscript and includes (in alphabetical order): Gert Bronfort, Norm Buckley, Lisa Carlesso, Linda Carroll, Pierre Côté, Jeanette Ezzo, Paulo Ferreira, Tim Flynn, Charlie Goldsmith, Anita
Gross, Ted Haines, Jan Hartvigsen, Wayne Hing, Gwendolen Jull, Faith Kaplan, Ron Kaplan, Helge Kasch, Justin Kenardy, Per Kjær, Janet Lowcock, Joy MacDermid, Jordan Miller, Margareta Nordin, Paul Peloso, Jan Pool, Duncan Reid, Sidney Rubinstein, P. Lina Santaguida, Anne Söderlund, Natalie Spearing, Michele Sterling, Grace Szeto, Robert Teasell, Arianne Verhagen, David M. Walton, Marc White.

This work was supported by Canadian Institutes of Health Research (CIHR) grant(s) FRN: KRS-102084.

\section{REFERENCES}

[1] Sterling M, Pedler A. A neuropathic pain component is common in acute whiplash and associated with a more complex clinical presentation. Man Ther 2009; 14(2): 173-9.

[2] Prushansky T, Dvir Z. Cervical motion testing: methodology and clinical implications. J Manipulative Physiol Ther 2008; 31(7): 503-8.

[3] Sterling M. Testing for sensory hypersensitivity or central hyperexcitability associated with cervical spine pain. J Manipulative Physiol Ther 2008; 31(7): 534-9.

[4] Knox JJ, Beilstein DJ, Charles SD, et al. Changes in head and neck position have a greater effect on elbow joint position sense in people with whiplash-associated disorders. Clin J Pain 2006; 22(6): 512-8.

[5] Jull GA. Deep cervical flexor muscle dysfunction in whiplash. J Musculoskelet Pain 2000; 8(1-2): 143-54.

[6] Dvir Z, Prushansky T. Cervical muscles strength testing: methods and clinical implications. J Manipulative Physiol Ther 2008; 31(7): 518-24.

[7] Silva AG, Punt TD, Johnson MI. Reliability and validity of head posture assessment by observation and a four-category scale. Man Ther 2010; 15(5): 490-5.

[8] Silva AG, Punt TD, Sharples P, Vilas-Boas JP, Johnson MI. Head posture and neck pain of chronic nontraumatic origin: a comparison between patients and pain-free persons. Arch Phys Med Rehabil 2009; 90(4): 669-74.

[9] Silva AG, Cruz AL. Standing balance in patients with whiplashassociated neck pain and idiopathic neck pain when compared with asymptomatic participants: A systematic review. Physiother Theory Pract 2013; 29(1): 1-18.

[10] Feise RJ, Menke JM. Functional Rating Index: literature review. Med Sci Monit 2010; 16(2): RA25-36.

[11] MacDermid JC, Walton DM, Avery S, et al. Measurement properties of the neck disability index: a systematic review. J Orthop Sports Phys Ther 2009; 39(5): 400-17.

[12] Bot SD, Terwee CB, van der Windt DA, van der Beek AJ, Bouter LM, Dekker J. Work-related physical and psychosocial risk factors for sick leave in patients with neck or upper extremity complaints. Int Arch Occup Environ Health 2007; 80(8): 733-41.

[13] Buckle P. Upper limb disorders and work: the importance of physical and psychosocial factors. J Psychosom Res 1997; 43(1): 17-25.

[14] Cote P, Kristman V, Vidmar M, et al. The prevalence and incidence of work absenteeism involving neck pain: a cohort of Ontario lost-time claimants. Spine 2008; 33(Suppl 4): S192-8.

[15] Linton SJ. A review of psychological risk factors in back and neck pain. Spine 2000; 25(9): 1148-56.

[16] Sterling M, Kenardy J, Jull G, Vicenzino B. The development of psychological changes following whiplash injury. Pain 2003; 106(3): 481-9.

[17] Carlesso LC, Walton DM, MacDermid JC. Reflecting on whiplash associated disorder through a QoL lens: an option to advance practice and research. Disabil Rehabil 2012; 34(13): 1131-9.

[18] de Koning CH, van den Heuvel SP, Staal JB, Smits-Engelsman BC, Hendriks EJ. Clinimetric evaluation of methods to measure muscle functioning in patients with non-specific neck pain: a systematic review. BMC Musculoskelet Disord 2008; 9: 142.

[19] de Koning CH, van den Heuvel SP, Staal JB, Smits-Engelsman BC, Hendriks EJ. Clinimetric evaluation of active range of motion measures in patients with non-specific neck pain: a systematic review. [Review] [86 refs]. Eur Spine J 2008; 17(7): 905-21.

[20] van TE, Anderegg Q, Bossuyt PM, Lucas C. Inter-examiner reliability of passive assessment of intervertebral motion in the cervical and lumbar spine: a systematic review. Man Ther 2005; 10(4): 256-69.

[21] Nordin M, Carragee EJ, Hogg-Johnson S, et al. Assessment of neck pain and its associated disorders: results of the Bone and Joint Decade 
2000-2010 Task Force on Neck Pain and Its Associated Disorders. Spine 2008; 33(Suppl 4): S101-22.

[22] Abrams D, Davidson M, Harrick J, Harcourt P, Zylinski M, Clancy J. Monitoring the change: current trends in outcome measure usage in physiotherapy. Man Ther 2006; 11(1): 46-53.

[23] Dunckley M, Aspinal F, Addington-Hall JM, Hughes R, Higginson IJ. A research study to identify facilitators and barriers to outcome measure implementation. Int J Palliat Nurs 2005; 11(5): 218-5.

[24] Skeat J, Perry A. Exploring the implementation and use of outcome measurement in practice: a qualitative study. Int $\mathrm{J}$ Lang Commun Disord 2008; 43(2): 110-25.

[25] Novak CB. Evaluation of hand sensibility: a review. J Hand Ther 2001; 14(4): 266-72.

[26] Escolar-Reina P, Medina-Mirapeix F, Gascon-Canovas JJ, et al. How do care-provider and home exercise program characteristics affect patient adherence in chronic neck and back pain: a qualitative study. BMC Health Serv Res 2010; 10: 60.

[27] MacDermid JC, Walton D, Gross A, ICON. A qualitative description of neck pain has implications for classification. Pain Res Manage 2013 [Epub ahead of print].

[28] Mintken PE, Glynn P, Cleland JA. Psychometric properties of the shortened disabilities of the Arm, Shoulder, and Hand Questionnaire (QuickDASH) and Numeric Pain Rating Scale in patients with shoulder pain. J Shoulder Elbow Surg 2009; 18(6): 920-6.

[29] Vernon H. The Neck Disability Index: state-of-the-art, 1991-2008. J Manipulative Physiol Ther 2008; 31(7): 491-502.

[30] Lystad RP, Bell G, Bonnevie-Svendsen M, Carter CV. Manual therapy with and without vestibular rehabilitation for cervicogenic dizziness: a systematic review. Chiropr Man Therap 2011; 19(1): 21.

[31] Prins Y, Crous L, Louw QA. A systematic review of posture and psychosocial factors as contributors to upper quadrant musculoskeletal pain in children and adolescents. Physiother Theory Pract 2008; 24(4): 221-42.

[32] Nieto R, Miro J, Huguet A. Disability in subacute whiplash patients: usefulness of the neck disability index. Spine 2008; 33(18): E630-5.

[33] van der Velde G, Beaton DE, Hogg-Johnson SH, Hurwitz EL, Tenant A. Rasch analysis provides new insights into the measurement properties of the neck disability index. Arthritis Rheum 2009; 61(4): 544-51.

[34] Mehta S, MacDermid JC, Carlesso LC, McPhee C. Concurrent Validation of the DASH and the QuickDASH in Comparison to NeckSpecific Scales in Patients With Neck Pain. Spine (Phila Pa 1976 ) 2010; 35(24): 2150-6.

[35] Chan Ci EM, Clair DA, Edmondston SJ. Validity of the Neck Disability Index and Neck Pain and Disability Scale for measuring disability associated with chronic, non-traumatic neck pain. Man Ther 2009; 14(4): 433-8.

[36] Horn KK, Jennings S, Richardson G, Vliet DV, Hefford C, Abbott JH. The patient-specific functional scale: psychometrics, clinimetrics, and application as a clinical outcome measure. J Orthop Sports Phys Ther 2012; 42(1): 30-42.

[37] Pietrobon R, Coeytaux RR, Carey TS, Richardson WJ, DeVellis RF. Standard scales for measurement of functional outcome for cervical pain or dysfunction: a systematic review. Spine 2002; 27(5): 515-22.

[38] Westaway MD, Stratford PW, Binkley JM. The Patient-Specific Functional Scale: validation of its use in persons with neck dysfunction. J Orthop Sports Phys Ther 1998; 27(5): 331-8.
[39] Cleland JA, Fritz JM, Whitman JM, Palmer JA. The reliability and construct validity of the Neck Disability Index and patient specific functional scale in patients with cervical radiculopathy. Spine 2006; 31(5): 598-602.

[40] Michlovitz SL, LaStayo PC, Alzner S, Watson E. Distal radius fractures: therapy practice patterns. J Hand Ther 2001; 14(4): 249-57.

[41] Caneiro JP, O'Sullivan P, Burnett A, et al. The influence of different sitting postures on head/neck posture and muscle activity. Man Ther 2010; 15(1): 54-60.

[42] Yip CH, Chiu TT, Poon AT. The relationship between head posture and severity and disability of patients with neck pain. Man Ther 2008; 13(2): 148-54.

[43] Edmondston SJ, Chan HY, Ngai GC, et al. Postural neck pain: an investigation of habitual sitting posture, perception of 'good' posture and cervicothoracic kinaesthesia. Man Ther 2007; 12(4): 363-71.

[44] Brismee JM, Gipson D, Ivie D, et al. Interrater reliability of a passive physiological intervertebral motion test in the mid-thoracic spine. J Manipulative Physiol Ther 2006; 29(5): 368-73.

[45] Pool JJ, Hoving JL, de Vet HC, van MH, Bouter LM. The interexaminer reproducibility of physical examination of the cervical spine. J Manipulative Physiol Ther 2004; 27(2): 84-90.

[46] Passier LN, Nasciemento MP, Gesch JM, Haines TP. Physiotherapist observation of head and neck alignment. Physiother Theory Pract 2010; 26(6): 416-23.

[47] Silva AG, Sharples P, Johnson MI. Studies comparing surrogate measures for head posture in individuals with and without neck pain. Phys Ther Rev 2010; 15: 12-22.

[48] Ylinen J, Takala EP, Nykanen M, et al. Active neck muscle training in the treatment of chronic neck pain in women: a randomized controlled trial. JAMA 2003; 289(19): 2509-16.

[49] Scott D, Jull G, Sterling M. Widespread sensory hypersensitivity is a feature of chronic whiplash-associated disorder but not chronic idiopathic neck pain. Clin J Pain 2005; 21(2): 175-81.

[50] Sterling M, Jull G, Vicenzino B, Kenardy J. Sensory hypersensitivity occurs soon after whiplash injury and is associated with poor recovery. Pain 2003; 104(3): 509-17.

[51] Walton DM, MacDermid JC, Nielson W, Teasell RW, Chiasson M, Brown L. Reliability, standard error, and minimum detectable change of clinical pressure pain threshold testing in people with and without acute neck pain. J Orthop Sports Phys Ther 2011; 41(9): 644-50.

[52] Antonaci F, Sand T, Lucas GA. Pressure algometry in healthy subjects: inter-examiner variability. Scand J Rehabil Med 1998; 30(1): 3-8.

[53] Jerosch-Herold C. A study of the relative responsiveness of five sensibility tests for assessment of recovery after median nerve injury and repair. J Hand Surg Br 2003; 28(3): 255-60.

[54] Jerosch-Herold C, Rosen B, Shepstone L. The reliability and validity of the locognosia test after injuries to peripheral nerves in the hand. J Bone Joint Surg Br 2006; 88(8): 1048-52.

[55] Jerosch-Herold C, Shepstone L, Miller L, Chapman P. The responsiveness of sensibility and strength tests in patients undergoing carpal tunnel decompression. BMC Musculoskelet Disord 2011; 12: 244.

[56] Scherer M, Schaefer H, Blozik E, Chenot JF, Himmel W. The experience and management of neck pain in general practice: the patients' perspective. Eur Spine J 2010; 19(6): 963-71. 